\title{
$\beta$-diversity of deep-sea holothurians and asteroids along a bathymetric gradient (NE Atlantic)
}

\author{
Martine C. Wagstaff ${ }^{1, *}$, Kerry L. Howell ${ }^{2}$, Brian J. Bett ${ }^{3}$, David S. M. Billett ${ }^{3}$, \\ Solange Brault ${ }^{1}$, Carol T. Stuart ${ }^{1}$, Michael A. Rex ${ }^{1}$ \\ ${ }^{1}$ Department of Biology, University of Massachusetts, 100 Morrissey Blvd, Boston, MA 02125 \\ ${ }^{2}$ University of Plymouth, Drake Circus, Plymouth PL4 8AA, UK \\ ${ }^{3}$ National Oceanography Centre, Southampton SO14 3ZH, UK
}

\begin{abstract}
Measuring and understanding patterns of $\beta$-diversity remain major challenges in community ecology. Recently, $\beta$-diversity has been shown to consist of 2 distinct components: (1) spatial turnover and (2) species loss leading to nestedness. Both components structure deep-sea macrofaunal assemblages but vary in importance among taxa and ocean basins and with energy availability. Here, we present the first evidence for turnover and nestedness along a bathymetric gradient in 2 major megafaunal taxa, holothurians and asteroids. Turnover is the dominant component of $\beta$-diversity throughout bathyal and abyssal zones in both taxa, despite major differences in $\alpha$-diversity and trophic composition. High spatial turnover suggests a role for evolutionary adaptation to environmental circumstances within depth bands. This pattern differs fundamentally from those in some macrofaunal groups in low-energy environments where abyssal nestedness is high and diversity low, with diversity maintained partly by source-sink dynamics.
\end{abstract}

KEY WORDS: Beta diversity - Nestedness - Turnover - Source-sink dynamics · Deep sea · Echinoderms $\cdot$ Asteroids $\cdot$ Holothurians

\section{INTRODUCTION}

Much is known about patterns of deep-sea $\alpha$-diversity and their potential ecological and evolutionary drivers (Rex \& Etter 2010). However, measuring patterns of $\beta$-diversity and understanding their underlying causes remain daunting challenges (Carney 2005, Wei et al. 2010a). Historically, in deep-sea eco$\operatorname{logy}, \beta$-diversity has been referred to as 'zonation,' meaning depth zones of relatively little faunal change, separated by more abrupt shifts called boundaries (Le Danois 1948). With improved sampling, it became apparent that most faunal change with depth is gradual and continuous unless interrupted by major topographic features or sharp changes in oceanographic conditions (Rex \& Etter 2010). We prefer to use term $\beta$-diversity because it is more widely used in ecology and makes studies of variation in faunal

\footnotetext{
*Corresponding author: martine.wagstaff001@umb.edu
}

makeup in the deep sea more accessible to ecologists working in other systems.

Deep-sea $\beta$-diversity has been interpreted mainly as a process of species replacement along bathymetric (Carney 2005) and horizontal (McClain \& Hardy 2010) environmental gradients. However, $\beta$-diversity has 2 distinct components: spatial replacement of species (turnover), and species loss leading to nestedness (Baselga 2010, 2012). Nestedness is when smaller communities are ordered subsets of species assemblages in larger communities. Both species turnover and nestedness can contribute to $\beta$-diversity in deepsea communities (Brault et al. 2013a,b).

One of the strongest environmental gradients in the deep sea is the exponential decrease in food supply from particulate organic carbon (POC) flux to the sea floor with increasing depth. At abyssal depths ( $>4000 \mathrm{~m}$ ), severely low food supply can limit species

() The authors 2014. Open Access under Creative Commons by Attribution Licence. Use, distribution and reproduction are unrestricted. Authors and original publication must be credited. 
diversity (Tittensor et al. 2011, McClain et al. 2012). In macrofaunal molluscs, with depressed abyssal diversity, abyssal communities are nested subsets of lower bathyal communities. These depauperate abyssal communities are essentially composed of bathyal species whose depth range extensions are made possible through larval dispersal. This suggests that some abyssal populations may be sinks that are maintained by continued immigration from more abundant bathyal sources (Rex et al. 2005). Where abyssal diversity is not depressed, because POC-flux remains relatively high, turnover dominates at all depths and abyssal assemblages contain more endemic species (Brault et al. 2013b).

We examine bathymetric trends in $\alpha$ - and $\beta$-diversity in megafaunal asteroids and holothurians in the NE Atlantic to determine the relative importance of turnover and nestedness. This is the first time nestedness versus turnover has been measured in megafaunal taxa. Megafaunal density and biomass decrease more rapidly with depth than for the macrofauna, presumably because large organisms have higher energy demands and are more vulnerable to the decline in food supply with depth (Rex et al. 2006, Wei et al. 2010b). Our initial hypothesis was that nestedness $\beta$-diversity should predominate in assemblages of reduced diversity, whereas turnover $\beta$-diversity should predominate where abyssal diversity remains high.

\section{METHODS}

\section{Geographic setting, biogeographic patterns, and echinoderm biology}

We compare $\alpha$-diversity, depth distributions, and $\beta$-diversity of holothurians and asteroids collected from the Porcupine Seabight (PSB) and Porcupine Abyssal Plain (PAP) in the eastern North Atlantic. The PSB is an amphitheater-shaped embayment in the Irish continental margin that opens to the adjacent abyssal plain at $4000 \mathrm{~m}$ (Rice et al. 1991). In the following, we refer to depths $>4000 \mathrm{~m}$ as abyssal as this depth physiographically marks the beginning of the abyssal plain.

The data represent 160 and 209 epibenthic sledge and semi-balloon otter trawl samples for holothurians and asteroids respectively (131 samples are shared) taken over a $21 \mathrm{yr}$ period from 1977 to 1998 as part of the Institute of Oceanographic Sciences Biology Programme in the PSB (Rice et al. 1991) and the BENGAL Program in the PAP (Billett \& Rice 2001) (for a map of sampling stations, please see Howell et al. 2002). The samples include 43 species of holothurians (Billett 1991) and 43 species of asteroids (Howell et al. 2002). To meet the matrix size and fill requirements of the analytical methods, we first binned stations into $250 \mathrm{~m}$ depth increments. This bin size also seemed to capture variation in depth ranges and diversity. Using different bin sizes of 100 to $1000 \mathrm{~m}$ did not affect our results. No depth increment explored indicated effects of major hydrological or physiographic features. We then created binary presence-absence matrices of species occurrences in each depth bin. Abundance data are reported by Billett (1991) and Howell et al. (2002). Highest population densities are not found consistently in any part of the depth distributions. We used only records of positive occurrence within a depth bin and presence/absence data in our analyses because this is the most conservative approach. However, we illustrated ranges (Figs. 1 \& 2) as though they were fully occupied. We estimated $\alpha$-diversity as the number of co-occurring species in a depth bin (positive occurrences only).

Following the practice of several other studies (e.g. Billett 1991, Jangoux 1982, Roberts \& Moore 1997, Iken et al. 2001, Gale et al. 2013), we also attempted to classify the feeding types of the species present (in the case of the asteroids, we supply additional information on feeding type in Table $\mathrm{S} 1$ in the supplement at www.int-res-com/articles/suppl/m508 p177_supp.pdf). Deep-sea holothurians are typically deposit feeders (Billett 1991) (Fig. 1). Different deposit-feeding modes exist (Roberts \& Moore 1997), although we were not able to infer those from our dataset. Asteroids are more trophically complex. Analysis of stomach contents is often uninformative because the majority of species have extraoral digestion and are flexible in their diet even intraspecifically (Jangoux 1982). Jangoux (1982, p. 117) describes the trophic biology of asteroids as being "at one and the same time an extensively studied topic and a still little known matter." The asteroid assemblage examined here includes carnivores (predators and scavengers), suspension feeders, and deposit feeders. For some species, direct evidence of diet and feeding types exists (although in many cases there is evidence for polytrophy between regions; see Table S1 in the Supplement). For the purpose of this analysis, we characterized a species according to the dominant feeding mode when known. For other species, we inferred diet based on information from either the same species at a different site or evidence from congeneric and confamilial species. If a group 


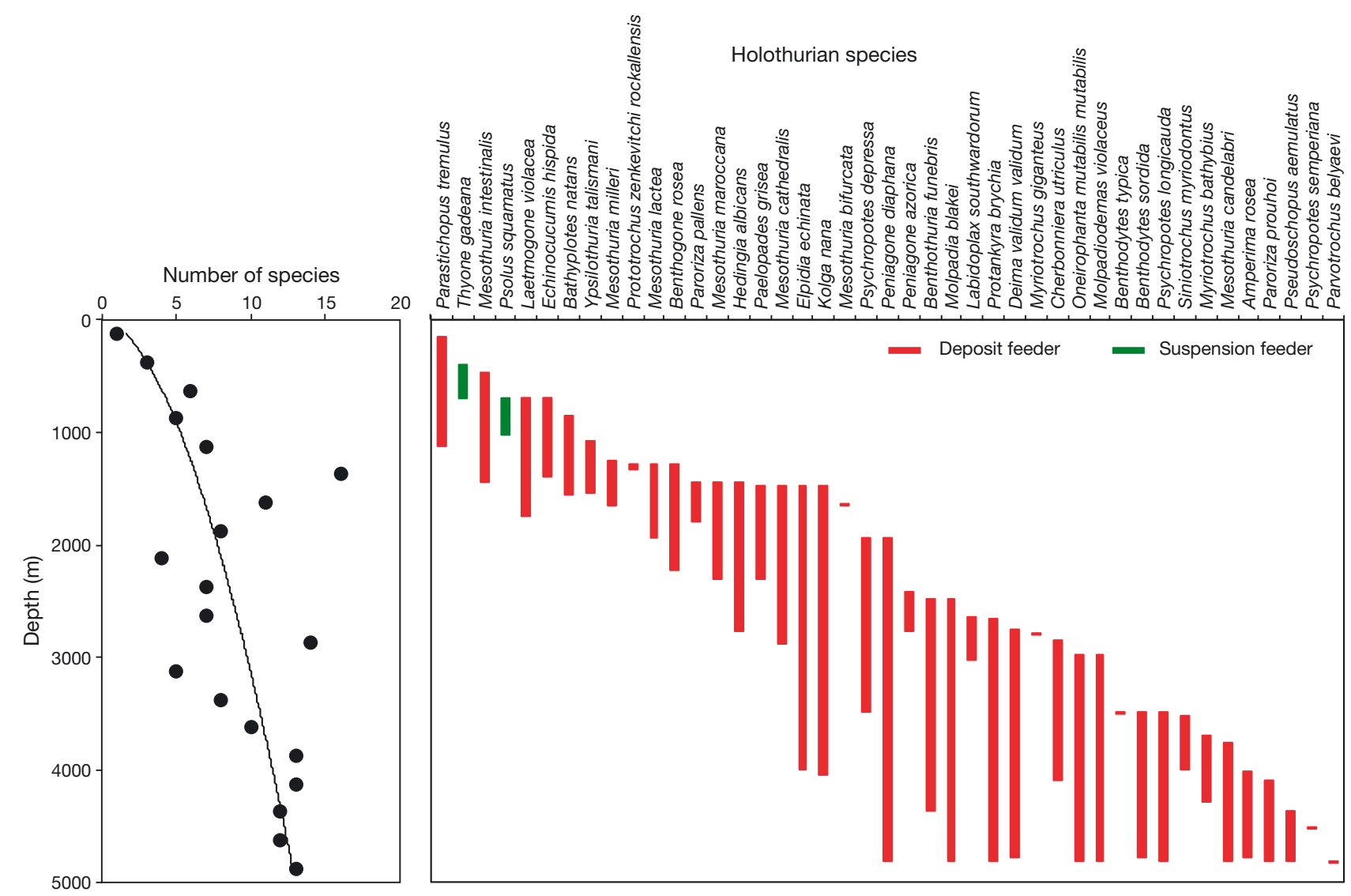

Fig. 1. Diversity (co-occurring species in $250 \mathrm{~m}$ depth bins, positive occurrences only), depth ranges (assumed continuous distributions), and feeding types for holothurians in the Porcupine Seabight and Abyssal Plain. Diversity data are fit with a power curve to show the general trend (Number of species $=0.1097 \times \operatorname{depth}^{0.5605}$; adjusted $\mathrm{R}^{2}=0.602, \mathrm{p}<0.01$ )

displays considerable polytrophy or is a little known species, we considered the trophic type to be unknown (8 species). More details on feeding types and how they were determined can be found in Table S1. The asteroid assemblage shows a shift from primarily carnivores to deposit feeders below 1800 m (Fig. 2).

While the mode of development is known for less than half of the species analyzed here (34\%), nearly all deep-sea asteroids and holothurians that have been studied are gonochoristic, reproduce continuously, and have a dispersal phase that is either a planktotrophic larva, a pelagic lecithotrophic larva, or direct development with a pelagic juvenile (Young 2003). It is very likely that the great majority of species have the dispersal ability to necessarily participate in metapopulation or source-sink dynamics at the regional spatial scale studied here.

\section{Analytical approach}

To determine the general trend in species composition over all depths, we performed non-metric multi- dimensional scaling (NMDS) on species presenceabsence matrices (Bray-Curtis dissimilarity index with 2 dimensions) using the metaMDS function in $\mathrm{R}$ (Faith et al. 1987, Minchin 1987).

For $\beta$-diversity analyses, we considered only the 1000 to $5000 \mathrm{~m}$ depth range. Diversity is depressed in the upper bathyal region (see 'Results'), and some species are shared with mid-bathyal depths. This complicates the analyses by revealing nestedness in the upper bathyal region (Brault et al. 2013a,b), which is not under investigation here as it is not a function of decreased ecological opportunity (i.e. POC-flux and animal density increase exponentially upslope).

Baselga $(2010,2012)$ showed that site-pairwise $\beta$ diversity, measured as the Sørensen (1948) dissimilarity index $\left(\beta_{\mathrm{s} ø r}\right)$, can be decomposed into 2 terms: dissimilarity resulting from turnover (spatial replacement) (Simpson 1943) $\left(\beta_{\text {sim }}\right)$, and dissimilarity attributed to nestedness $\left(\beta_{\text {nes }}\right)$. We used these measures to examine the differences in composition between 2 sites (pair-wise dissimilarity). Baselga $(2010,2012)$ also developed among-region metrics (multiple-site dissimilarity), $\beta_{\mathrm{S} ø \mathrm{R}}, \beta_{\mathrm{SIM}}$ and $\beta_{\mathrm{NES}}$. Subscripts in lower 


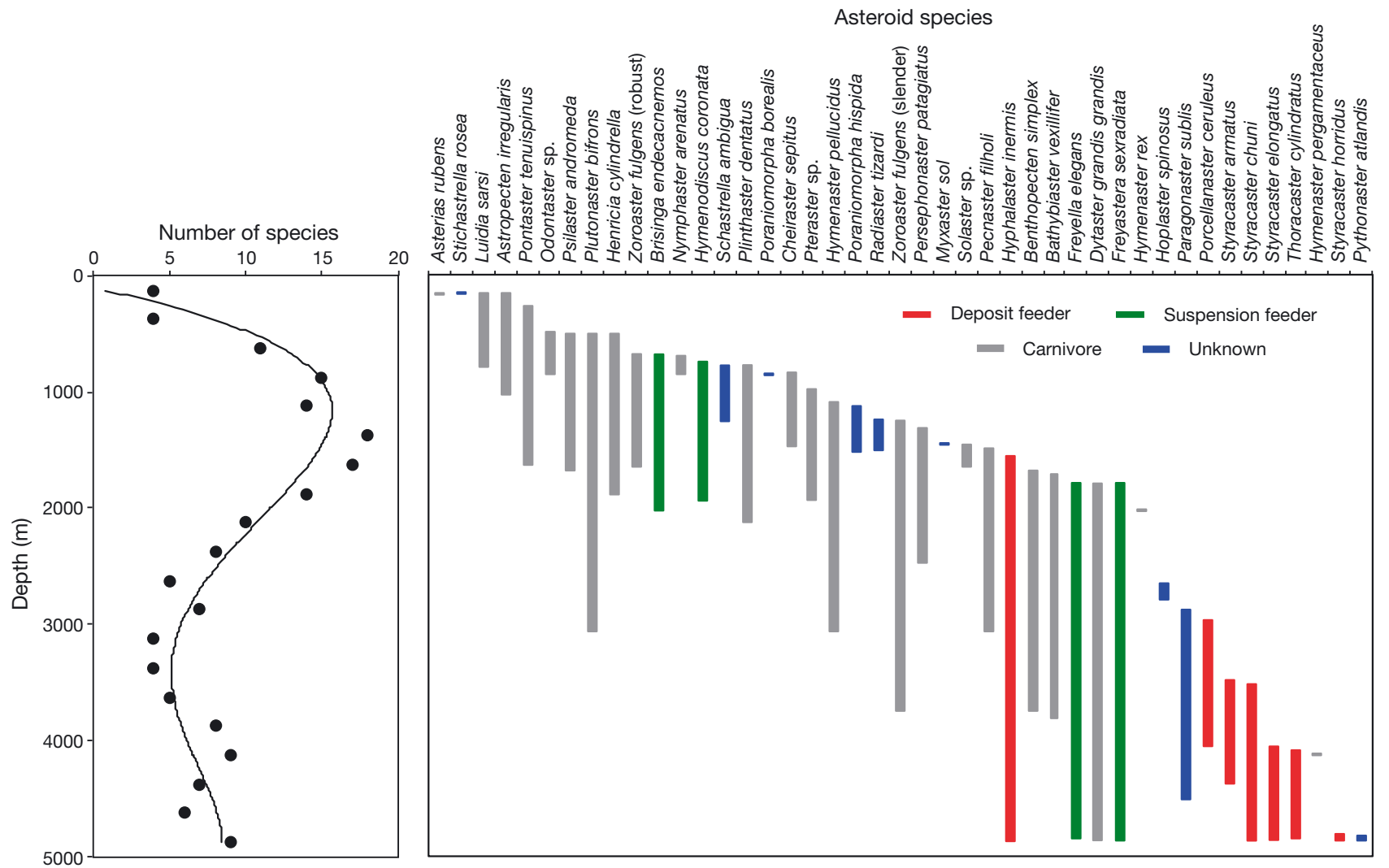

Fig. 2. Diversity (co-occurring species in $250 \mathrm{~m}$ depth bins, positive occurrences only), depth ranges (assumed continuous distributions), and feeding types for asteroids in the Porcupine Seabight and Abyssal Plain. Diversity data are fit with a fourth order polynomial to show the general trend (Number of species $=-2.544 \times \operatorname{depth}^{4}+4.487 \times \operatorname{depth}^{3}+4.487 \times \operatorname{depth}^{2}+-9.182 \times$ depth $+8.136 ;$ adjusted $\left.\mathrm{R}^{2}=0.754, \mathrm{p}<0.01\right)$

and upper case refer to pair-wise and multiple-site metrics respectively. The multiple-site dissimilarity comparisons have no statistics associated with them, but their relative values should be consistent with the general outcome of the among-site analysis. Analyses were carried out in $\mathrm{R}$ using the files ' $\beta$-pairwise. $R$ ' and ' $\beta$-multi.R' (Baselga 2010). In ' $\beta$-pairwise. $R$ ', we used the functions $\beta \cdot \operatorname{sør}(x), \beta \cdot \operatorname{sim}(x)$, and $\beta . n e s(x)$ to calculate $\beta_{\text {sor, }} \beta_{\text {sim, }}$ and $\beta_{\text {nes }}$ respectively, where $x$ was our binary presence-absence matrix in which sites were rows and species were columns. We similarly employed ' $\beta$-multi.R' and the functions $\beta . S \varnothing R(x)$, $\beta . \operatorname{SIM}(\mathrm{x})$, and $\beta . N E S(\mathrm{x})$.

Following Baselga (2010, 2012), we analyzed trends in $\beta$-diversity components as a function of depth separation among all pairs of sites (depth bins) for both datasets using a Mantel test with Pearson's correlation (Legendre \& Legendre 1998). We compared slopes for the different dissimilarity indices as a function of depth separation between the taxa. First, we estimated the frequency distributions of the parameters by bootstrapping, using the boot package (Canty \& Ripley 2008), to retrieve a frequency distribution of
1000 slopes and intercepts. We then tested for significant differences between slopes by computing the probability of obtaining the opposite result by chance when comparing the estimated distribution of parameters. Where there were no depth-related trends, we used a Kruskal-Wallis test to identify differences in median values of dissimilarity between the 2 classes of echinoderms.

In 2 earlier papers, we divided these analyses into 2 broad depth regimes (1000 to $3000 \mathrm{~m}$ and 3000 to $5000 \mathrm{~m}$ ) in an attempt to identify the relative importance of turnover and nestedness with depth (Brault et al. $2013 \mathrm{a}, \mathrm{b})$. A preliminary analysis of the echinoderm data showed no difference in either nestedness or turnover between shallower and deeper depth segments. Consequently, we analyzed data over the full depth range.

We performed analyses of nestedness per se by applying BINMATNEST (Rodríguez-Gironés \& Santamaría 2006) to a data matrix of species as rows and sites as columns. This analysis provides a measure of nested order, which was compared to a distribution of 1000 nulls (we used the most conservative null 
model). BINMATNEST assigns sites with a nested rank order (Stiles \& Scheiner 2008), and it is for this reason that we used this program over others. As we are concerned with the direction of nestedness, we were then able to regress nested rank order against depth. For asteroids, nested rank order was also correlated with the proportion of deposit feeders in a depth bin (Fig. 2). We used the Kendall rank correlation coefficient $(\tau)$ to establish the relationships between nestedness rank, depth, and feeding type.

\section{RESULTS}

Figs. $1 \& 2$ show depth-related patterns of $\alpha$ - and $\beta$-diversity. Both taxa (asteroids and holothurians) show clear changes in species composition with depth, and the abyssal faunas do include range extensions of bathyal species. Holothurians show an increase in $\alpha$-diversity with depth. Asteroid $\alpha$-diversity peaks at $1000 \mathrm{~m}$ and then decreases with a slight increase again in the abyss. The asteroid assemblage shows a shift from primarily carnivores to deposit feeders, below 1800 m (Fig. 2).

Plots of the normalised (standard normal cumulative distribution with a mean of 0 and a standard deviation of 1) NMDS $x$-value output against depth showed steady and similar rates of faunal change (Fig. 3). The first axis of NMDS is a common way to show the general trend of $\beta$-diversity (see Howell et al. 2002). In this case, it shows that the 2 taxa have similar overall trends. Spearman's rank correlation coefficients were high for both holothurians $\left(\mathrm{r}_{\mathrm{s}}=0.96\right.$, $\mathrm{p}<0.001)$ and asteroids $\left(\mathrm{r}_{\mathrm{s}}=0.99, \mathrm{p}<0.001\right)$.

Analysis of $\beta_{\mathrm{s} ø r}, \beta_{\mathrm{sim}}$, and $\beta_{\text {nes }}$ as a function of depth difference for both echinoderm classes yielded the following patterns (Fig. 4): overall dissimilarity, $\beta_{\text {sør }}$ increased significantly with depth separation for both holothurians and asteroids; turnover dissimilarity, $\beta_{\text {sim, }}$ also increased significantly with depth for both classes; nestedness dissimilarity, $\beta_{\text {nes, }}$ showed no depth-related trends. A comparison of the dissimilarity relationships as a function of depth separation between classes showed no differences between the slopes for $\beta_{\text {sør }}(p>0.05)$ or $\beta_{\text {sim }}(p>0.05)$ or for intercepts $\beta_{\text {sør }}(p>0.05)$ or $\beta_{\text {sim }}(p>0.05)$. The analysis presented in Fig. 4 is the usual way (see Baselga 2010, 2012) of contrasting turnover and nestedness along a gradient (by distance, or depth difference in this case). It shows that the turnover component of $\beta$-diversity is pervasive across all depths in these taxa. This analysis makes it possible to determine the relative importance of turnover and nestedness in a quan-

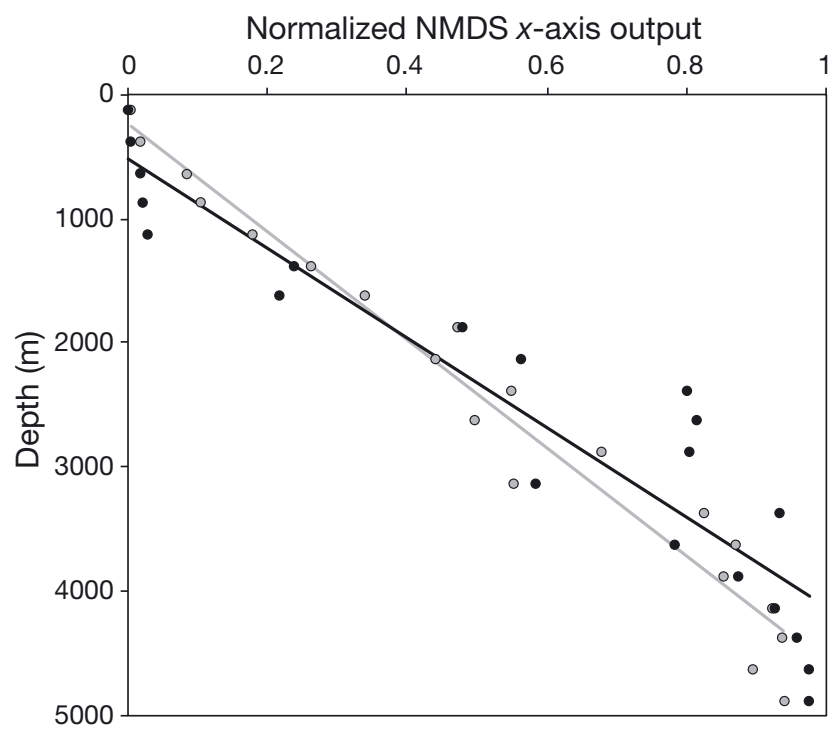

Fig. 3. Plots of normalized (standard normal cumulative distribution with a mean of 0 and a SD of 1) NMDS $x$-value output against depth for holothurians (black) and asteroids (grey) in the Porcupine Seabight and Abyssal Plain. Holothurian normalized NMDS $\mathrm{x}$-axis output $=-0.0616+0.0002$ $x$ depth, $\mathrm{p} \ll 0.001$; asteroid normalized NMDS $\mathrm{x}$-axis output $=-0.0315+0.0002 \times$ depth,$p \ll 0.001$. Although the relationship for holothurians appears to have a curvilinear tendency, it is not significantly different from a linear relationship ( $\mathrm{R}^{2}$ values are 0.9140 for exponential curvilinear and 0.8821 for linear)

titative way. Although nestedness dissimilarity $\left(\beta_{\text {nes }}\right)$ shows no depth-related trends for either holothurians or asteroids, the median value is significantly higher for asteroids (0.067) than for holothurians (0.031) (Kruskal-Wallis $\chi^{2}=7.92, \mathrm{p}=0.0049$ ). Multiple-site dissimilarities yield a similar pattern. For holothurians, $\beta_{\mathrm{S} \varnothing \mathrm{R}}=0.88, \beta_{\mathrm{SIM}}=0.84$, and $\beta_{\mathrm{NES}}=0.04$; and for asteroids, $\beta_{\mathrm{S} \varnothing \mathrm{R}}=0.88, \beta_{\mathrm{SIM}}=0.81$, and $\beta_{\mathrm{NES}}=0.06$, generally supporting the pairwise results. This analysis suggests that overall $\beta$-diversity increases with depth separation for both taxa and that turnover is the dominant component of $\beta$-diversity with little evidence of nestedness dissimilarity in either taxon.

Using BINMATNEST, nested order for both holothurians $(p<0.02)$ and asteroids $(p=0.01)$ was lower than null expectations, indicating that the assemblages are more structured than expected by chance along the depth gradient. Nested rank order, however, was not correlated with depth for holothurians $(\tau=$ -0.067, $\mathrm{p}=0.66, \mathrm{n}=16$ ). For asteroids, the correlation is significant ( $\tau=0.43, \mathrm{p}=0.02, \mathrm{n}=16$ ), but the relationship is not convincingly monotonic (see Fig. S1 in the supplement at www.int-res.com/articles/suppl/ m508p177_supp.pdf). Thus, there is no compelling evidence of nestedness increasing towards the abyss. 

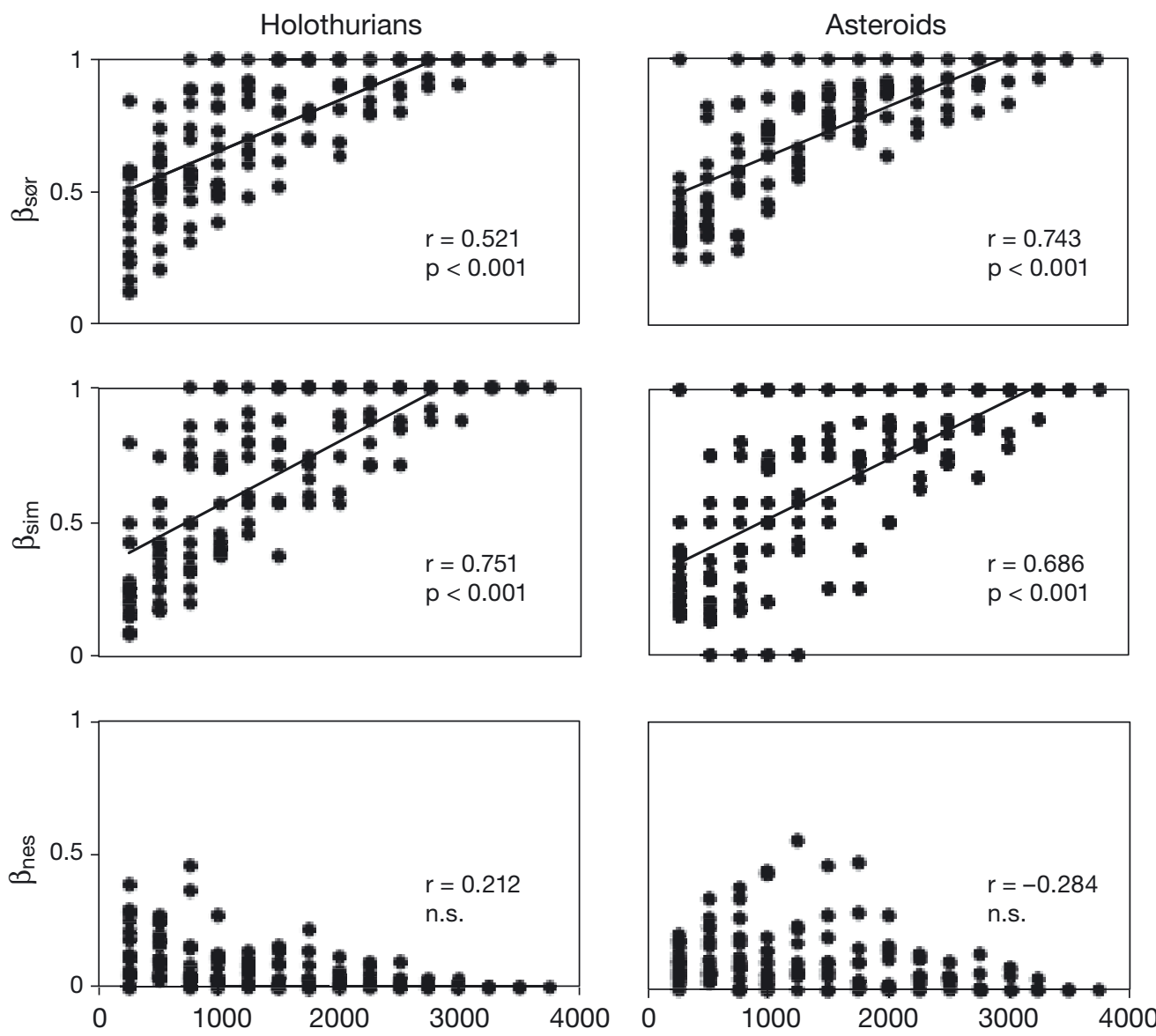

Fig. 4. Baselga's (2010) pair-wise dissimilarity of holothurian and asteroid assemblages as a function of depth difference for comparisons among all sites in the Porcupine Seabight and Abyssal Plain. Dissimilarity ranges from 0 (identical species composition) to 1 (completely different species composition). p-values indicate significance of Pearson's correlation r. Regressions shown where correlations were significant $\left(\beta_{\text {sør }}\right.$ holothurians $=0.459+0.0002 \times$ depth, $p<0.0001 ; \beta_{\text {sim }}$ holothurians $=0.327+$ $0.0002 \times$ depth, $\mathrm{p} \ll 0.001 ; \beta_{\mathrm{s} ø \mathrm{r}}$ asteroids $=0.446+0.0002 \times$ depth, $\mathrm{p} \ll 0.001 ; \beta_{\text {sim }}$ asteroids $=0.291+0.0002 \times$ depth, $\left.\mathrm{p} \ll 0.001\right)$

If anything, both taxa show peak nestedness at intermediate depths and a decline in nestedness both up and down slope (Fig. S1). This is probably a result of there being relatively high levels of regional endemism within the upper bathyal and abyssal zones and a transitional region of species with broad depth ranges at intermediate depths (cf. Billett 1991, his Fig. 12, and Howell et al. 2002, their Fig. 3). The proportion of deposit feeding asteroids is positively correlated with depth $(\tau=0.66, \mathrm{p}<0.001, \mathrm{n}=16)$, confirming the earlier impression of a shift from carnivory to deposit feeding. The incidence of deposit feeding is not related to nested rank order $(\tau=0.19, \mathrm{p}=0.17, \mathrm{n}=16)$.

\section{DISCUSSION}

Although holothurians and asteroids in the PSB and PAP display different patterns of $\alpha$-diversity
(Figs. $1 \&$ 2) and have very different trophic compositions, they have remarkably similar patterns of $\beta$ diversity (Fig. 4). The overall measure of $\beta$-diversity increases with depth separation for both taxa, and turnover is the dominant component of $\beta$-diversity. Some nestedness does occur, as indicated by the BINMATNEST results, but there is little evidence of consistent down-slope nestedness in either taxon.

Holothurians show increased $\alpha$-diversity with depth and can be quite abundant in the abyss, possibly because of the ability of some species to rapidly exploit seabed accumulations of phytodetritus, which occur seasonally on the PAP (Billett et al. 2001, 2010). Since populations remain abundant in the abyss, they are unlikely to be maintained by source-sink dynamics that rely on immigration from bathyal source populations. Abyssal populations may still function as a metapopulation if phytodetritus accumulations are patchy on scales that conform to the spatial extent of 
populations and the temporal patterns of their life cycles. Unlike holothurians, asteroids show a reduced $\alpha$-diversity in the abyss. Carnivorous sea stars are probably more subject to the decrease in available energy with depth because they occupy a higher trophic level than deposit feeders, such as the infaunal mud-swallowing porcellanasterid species Hyphalaster and Styracaster, which replace them at greater depths. Extreme depths might impose selection for feeding modes closer to the base of the trophic structure. We expected asteroids to show nested effects in the abyss essentially as a diminished bathyal fauna-this was not the case. There is no convincing bathymetric evidence for abyssal nestedness as a consequence of source-sink dynamics in either taxon.

$\beta$-diversity in these 2 megafaunal elements differ from those found using the same analytical methods in molluscs (Brault et al. 2013a,b). Predatory neogastropods in the eastern North Atlantic show a progressive increase in nestedness below $1000 \mathrm{~m}$, and the rank order of nestedness is negatively predicted by macrofaunal density, reflecting the probability of local extinction, and positively by the proportion of species with dispersing larvae, reflecting immigration potential from bathyal sources. These results support a role for source-sink dynamics in maintaining abyssal populations. Since neogastropods represent a top trophic level in the macrofauna, they may be especially subject to the reduction of available energy with depth.

In bivalves, which represent a mixed assemblage of deposit feeders, suspension feeders, and carnivores and hence collectively occupy a lower trophic position than neogastropods, diversity increases with depth in the eastern North Atlantic (Brault et al. 2013b). Turnover dominates at all depths, and abyssal endemism consequently remains high. These patterns differ from western North Atlantic bivalve fauna where abyssal diversity is depressed, abyssal assemblages are nested subsets of the bathyal fauna, and deposit feeders dominate. This east-west difference in abyssal communities is consistent with higher production in the eastern basin (see e.g. Behrenfeld \& Falkowski 1997, Sun et al. 2006, Lutz et al. 2007, Brault et al. 2013b), which could support higher species diversity, permit a more complex trophic structure, and provide increased opportunity for adaptation to abyssal conditions resulting in endemism (Brault et al. 2013b). Ideally, we would also have a western North Atlantic data set for holothurians and asteroids so we could draw comparisons between turnover and nestedness in low- versus high-productivity regions.
Nestedness in abyssal assemblages can be an important part of $\beta$-diversity in the deep sea, but one that has a simple explanation. It is an ordered reduction of a richer bathyal fauna that is ultimately driven by resource limitation at great depths. Extreme energy deprivation encountered at the bathyal-abyssal transition may also act as a biogeographic filter that determines abyssal community composition. For example, in the western North Atlantic, abyssal gastropod assemblages largely comprise a subset of lower bathyal species that are typically smaller, have shell architectures that are energetically efficient, and are deposit feeders residing at the base of the trophic structure (McClain 2004, McClain et al. 2005, 2009). All of these characteristics are consistent with pre-adaptation to reduced energy availability.

The turnover component of $\beta$-diversity, found throughout the depth range of holothurians and asteroids analyzed here and in more productive abyssal situations in molluscs, is much more difficult to explain. In general, spatial turnover in species composition can be related to a combination of extrinsic ecological factors such as environmental heterogeneity, habitat type, biotic interactions, and barriers to dispersal (Whittaker 1960, Terborgh 1977, Gaston et al. 2007); intrinsic properties of species such as dispersal ability, body size, and feeding mode (Soininen et al. 2007a); past climate and geological conditions (Leprieur et al. 2011); and historical-evolutionary processes such as adaptation to ecological opportunities arrayed along resource gradients, speciation, and adaptive radiation (Qian et al. 2005, Soininen et al. 2007b).

All of these factors could affect biogeographic ranges in deep-sea organisms as well (McClain \& Hardy 2010), but how they operate in this remote and only recently explored environment remains unclear. Species-habitat associations are known for only a minute fraction of deep-sea species (Carney 2005, Rex \& Etter 2010). One promising approach to begin understanding this problem in broad outline is to separate out the spatial replacement and species loss components of $\beta$-diversity, as we have done here, and identify potential adaptive properties of species in abyssal assemblages that accompany species loss (McClain 2004, McClain et al. 2005, 2009, Rex et al. 2005). McClain et al. (2012) recently introduced a powerful approach, which is to relate distance decay of taxonomic, functional, and phylogenetic composition in deep-sea bivalves to measures of environmental filtering (primarily energy availability) and dispersal limitation. Turnover in all 3 compositional variables was influenced by both environmental filtering and 
dispersal limitation. Environmental filtering was stronger than dispersal limitation (spatial distance), suggesting that niche requirements are an important part of $\beta$-diversity in the deep sea but that dispersal is pervasive at regional scales. Source-sink dynamics (Rex et al. 2005), environmental species sorting (McClain et al. 2012), and regional enrichment (Stuart \& Rex 1994) in deep-sea molluscs all require extensive dispersal ability to operate. Disentangling the species-replacement and species-loss components of $\beta$-diversity, and relating distance decay to environmental factors and dispersal limitation in other taxa with different natural histories and at different scales, would be a major advance in understanding community structure in the deep sea.

One important conclusion, insofar as echinoderms and molluscs are representative of deep-sea communities, is that turnover dominates at bathyal depths irrespective of taxon, body size, and trophic role. The rate of change in depth with distance is greater in the bathyal zone than in the abyss, making bathyal environmental gradients stronger. The bathyal zone is also a more heterogeneous environment in terms of topography and habitat types (Rex \& Etter 2010). It is also a region of steep genetic and phenotypic clinal changes that indicate population differentiation and adaptation to local circumstances (Etter \& Rex 1990, Etter et al. 2005, 2011). Whether turnover continues to dominate in the abyss appears to depend on food supply. If POC-flux is sufficient to support abundant populations and a diverse community, adaptation to the abyssal environment, as reflected in higher endemism, occurs. However, if energy constraints become more extreme, the abyssal assemblage becomes a progressively reduced subset of lower bathyal species that essentially represents a mass effect. If this interpretation is correct, then both $\alpha$ - and $\beta$-diversity are influenced by the level of productivity with depth.

Acknowledgements. We thank Werner Ulrich, Andrés Baselga and Miguel Rodríguez-Gironés for use of their computer programs to calculate nestedness, and for much useful advice. This research was supported by NSF Grant OCE1129612 to M.A.R., S.B., and C.T.S.

\section{LITERATURE CITED}

Baselga A (2010) Partitioning the turnover and nestedness components of $\beta$ diversity. Glob Ecol Biogeogr 19:134-143

Baselga A (2012) The relationship between species replacement, dissimilarity derived from nestedness, and nestedness. Glob Ecol Biogeogr 21:1223-1232

Behrenfeld MJ, Falkowski PG (1997) Photosynthetic rates derived from satellite-based chlorophyll concentration. Limnol Oceanogr 42:1-20
Billett DSM (1991) Deep-sea holothurians. Oceanogr Mar Biol Annu Rev 29:259-317

Billett DSM, Rice AL (2001) The BENGAL programme: introduction and overview. Prog Oceanogr 50:13-25

> Billett DSM, Bett BJ, Rice AL, Thurston MH, and others (2001) Long-term change in the megabenthos of the Porcupine Abyssal Plain (NE Atlantic). Prog Oceanogr 50: 325-348

Billett DSM, Bett BJ, Reid WDK, Boorman B and others (2010) Long-term change in the abyssal NE Atlantic: the 'Amperima Event' revisited. Deep-Sea Res II 57:1406-1417

$>$ Brault S, Stuart CT, Wagstaff MC, Rex MA (2013a) Geographic evidence for source-sink dynamics in deep-sea neogastropods of the eastern North Atlantic: an approach using nested analysis. Glob Ecol Biogeogr 22: 433-439

> Brault S, Stuart CT, Wagstaff MC, McClain CR, and others (2013b) Contrasting patterns of $\alpha$-and $\beta$-diversity in deep-sea bivalves of the eastern and western North Atlantic. Deep-Sea Res II 92:157-164

Canty A, Ripley B (2008) Boot: bootstrap R (S-Plus) functions. R package version 1.2-32. R Foundation for Statistical Computing, Vienna, available at http://cran.rproject.org (accessed 25 Nov 2013)

Carney RS (2005) Zonation of deep biota on continental margins. Oceanogr Mar Biol Annu Rev 43:211-278

Etter RJ, Rex MA (1990) Population differentiation decreases with depth in deep-sea gastropods. Deep-Sea Res 37: 1251-1261

Etter RJ, Rex MA, Chase M, Quattro J (2005) Population differentiation decreases with depth in deep-sea bivalves. Evolution 59:1479-1491

> Etter RJ, Boyle EE, Glazier A, Jennings RM and others (2011) Phylogeography of a pan-Atlantic abyssal protobranch bivalve: implications for evolution in the deep Atlantic. Mol Ecol 20:829-843

Faith DP, Minchin PR, Belbin L (1987) Compositional dissimilarity as a robust measure of ecological distance. Vegetatio 69:57-68

> Gale KSP, Hamel JF, Mercier M (2013) Trophic ecology of deep-sea Asteroidea (Echinodermata) from eastern Canada. Deep-Sea Res I 80:25-36

Gaston KJ, Davies RG, Orme CDL, Olson VA and others (2007) Spatial turnover in the global avifauna. Proc R Soc Lond B 274:1567-1574

Howell KL, Billett DS, Tyler PA (2002) Depth-related distribution and abundance of seastars (Echinodermata: Asteroidea) in the Porcupine Seabight and Porcupine Abyssal Plain, NE Atlantic. Deep-Sea Res I 49:1901-1920

Iken K, Brey T, Wand U, Voigt J and others (2001) Food web structure of the benthic community at the Porcupine Abyssal Plain (NE Atlantic): a stable isotope analysis. Prog Oceanogr 50:383-405

Jangoux M (1982) Food and feeding mechanisms: Asteroidea. In: Jangoux M, Lawrence JM (eds) Echinoderm nutrition. AA Balkema Publishers, Rotterdam, p 117-159

Le Danois E (1948) Les profondeurs de la mer. Payot, Paris

Legendre P, Legendre L (1998) Numerical ecology, $2^{\text {nd }}$ edn. Elsevier, Amsterdam

> Leprieur F, Tedesco PA, Hugueny B, Beauchard O (2011) Partitioning global patterns of freshwater fish beta diversity reveals contrasting signatures of past climate changes. Ecol Lett 14:325-334

Lutz MJ, Caldeira K, Dunbar RB, Behrenfeld MJ (2007) Seasonal rhythms of net primary production and particulate 
organic carbon flux describe biological pump efficiency in the global ocean. J Geophys Res 112:C10011

McClain CR (2004) Connecting species richness, abundance and body size in deep-sea gastropods. Glob Ecol Biogeogr 13:327-334

McClain CR, Hardy SM (2010) The dynamics of biogeographic ranges in the deep sea. Proc R Soc Lond B 277: 3533-3546

McClain CR, Rex MA, Jabbour R (2005) Deconstructing bathymetric body size patterns in deep-sea gastropods. Mar Ecol Prog Ser 297:181-187

McClain CR, Rex MA, Etter R (2009) Patterns in deep-sea macroecology. In: Witman JD, Roy K (eds) Marine macroecology. University of Chicago Press, Chicago, IL, p 65-100

McClain CR, Allen AP, Tittensor DP, Rex MA (2012) Energetics of life on the deep seafloor. Proc Natl Acad Sci USA 109:15366-15371

Minchin PR (1987) An evaluation of relative robustness of techniques for ecological ordinations. Vegetatio 69: 89-107

> Qian H, Ricklefs RE, White PS (2005) Beta diversity of angiosperms in temperate floras of eastern Asia and eastern North America. Ecol Lett 8:15-22

Rex MA, Etter RJ (2010) Deep-sea biodiversity: pattern and scale. Harvard University Press, Cambridge, MA

> Rex MA, McClain CR, Johnson NA, Etter RJ (2005) A source-sink hypothesis for abyssal biodiversity. Am Nat 165:163-178

Rex MA, Etter RJ, Morris JS, Crouse J and others (2006) Global bathymetric patterns of standing stock and body size in the deep-sea benthos. Mar Ecol Prog Ser 317:1-8

Rice AL, Billett DSM, Thurston MH, Lampitt RS (1991) The Institute of Oceanographic Sciences biology programme in the Porcupine Seabight: background and general introduction. J Mar Biol Assoc UK 71:281-310

Roberts D, Moore HM (1997) Tentacular diversity in deepsea deposit-feeding holothurians: implications for biodiversity in the deep sea. Biodivers Conserv 6:1487-1505

Rodríguez-Gironés MA, Santamaría L (2006) A new algorithm to calculate the nestedness temperature of presence-absence matrices. J Biogeogr 33:924-935

Editorial responsibility: Paul Snelgrove, St. John's, Newfoundland and Labrador, Canada
Simpson GG (1943) Mammals and the nature of continents. Am J Sci 241:1-31

Soininen J, Lennon JJ, Hillebrand H (2007a) A multivariate analysis of beta diversity across organisms and environments. Ecology 88:2830-2838

Soininen J, McDonald R, Hillebrand H (2007b) The distance decay of similarity in ecological communities. Ecography 30:3-12

Sørensen TA (1948) A method of establishing groups of equal amplitude in plant sociology based on similarity of species content, and its application to analyses of the vegetation on Danish commons. Biol Skr 5:1-34

Stiles A, Scheiner SM (2008) Nestedness of remnant Sonoran Desert plant communities in metropolitan Phoenix, Arizona. Ecology 89:2473-2481

Stuart CT, Rex MA (1994) The relationship between developmental pattern and species diversity in deep-sea prosobranch snails. In: Young CM, Eckelbarger KJ (eds) Reproduction, larval biology, and recruitment of the deep-sea benthos. Columbia University Press, New York, NY, p 118-136

Sun X, Corliss BH, Brown CW, Showers WJ (2006) The effect of primary productivity and seasonality on the distribution of deep-sea benthic foraminifera in the North Atlantic. Deep-Sea Res I 53:28-47

Terborgh J (1977) Bird species diversity on an Andean elevational gradient. Ecology 58:1007-1019

> Tittensor DP, Rex MA, Stuart CT, McClain CR and others (2011) Species-energy relationships in deep-sea molluscs. Biol Lett 7:718-722

Wei C, Rowe GT, Hubbard GF, Scheltema AH and others (2010a) Bathymetric zonation of deep-sea macrofauna in relation to export of surface phytoplankton production. Mar Ecol Prog Ser 399:1-14

Wei C, Rowe GT, Escobar-Briones E, Boetius A and others (2010b) Global patterns and predictions of seafloor biomass using Random Forests. PLoS ONE 5:e15323

- Whittaker RH (1960) Vegetation of the Siskiyou mountains, Oregon and California. Ecol Monogr 30:279-338

Young CM (2003) Reproduction, development and lifehistory traits. In: Tyler P (ed) Ecosystems of the deep ocean. Elsevier, Amsterdam, p 381-426

Submitted: January 16, 2014; Accepted: May 20, 2014

Proofs received from author(s): July 18, 2014 